\title{
Microsaccades and Visual-Spatial Working Memory
}

\author{
Joshua T. Gaunt \\ University of California, \\ Santa Cruz
}

\author{
Bruce Bridgeman \\ University of California, \\ Santa Cruz
}

\begin{abstract}
Observers performed working memory tasks at varying retinal eccentricities, fixating centrally while microsaccade rates and directions were monitored. We show that microsaccades generate no interference in a working memory task, indicating that spatial working memory is at least partially insulated from oculomotor activity. Intervening tasks during the memory interval affected memory as well as microsaccade patterns. Average microsaccade rate peaks after appearance of a fixation cross at the start of a trial, and dips at cue onset and offset. Direction of stimuli in choice tasks did not influence microsaccade direction, however. Poorer memory accuracy for locations at greater retinal eccentricity calls for revising ideas of short-term spatial representations to include retinotopic or allocentric codes
\end{abstract}

Keywords: Eye movements, microsaccades, working memory

\section{Introduction}

The ability to remember and manipulate information is essential to human cognitive processes. Working memory (WM) is pervasive as a workspace for mental processes that make up momentary, explicit consciousness. Not only does the function of WM include simple temporary storage, or short-term memory (STM), but also more complex processes that manipulate and transform stored representations (Miyake \& Shah, 1999). There are several perspectives on the organization of these functions (Baddeley \& Hitch, 1974; Logie, 1995; Cowan, 1999; Cornoldi \& Vecchi, 2003); common among them is storage of short-term, domain-specific (verbal, visual, spatial) representations that are rehearsed, manipulated, or otherwise operated upon by active executive processes. Microsaccade patterns evoked during working memory tasks are less well understood.

\section{Dissociating Verbal and Spatial Working Memory}

Early neuropsychology supported a dissociation between verbal and visual-spatial WM (Gathercole, 1994), largely at a hemispheric level. Neuropsychological double dissociations are questionable at a finer grained level of analysis, however, because areas affected by focal brain damage are idiosyncratic across cases (Shallice, 1988).

Fortunately, behavioral paradigms also support a dissociation between verbal and visual-spatial information in normals (Baddeley, Grant, Wight \& Thomson, 1975; Smyth, Pearson, \& Pendleton, 1988; Logie, Zucco \& Baddeley, 1990; Hale et al., 1996; Cocchini, Logie, Della Sala, MacPherson \& Baddeley, 2002). Logie et al. compared letter spans with memory for visual matrix patterns (Wilson, Scott \& Power, 1987) when combined with either a secondary arithmetic or number imagery task. Number imagery interfered with visual span but not letter span, and vice-versa for interference from adding numbers. Although such studies suggest a wide diversity of information handled by VSWM, they clearly display independence from verbal WM. Long established is the idea of two visual systems, differentiating "what" and "how" systems (Bridgeman, Lewis, Heit \& Nagle, 1979; Bridgeman, Kirch \& Sperling, 1981; Ungerleider \& Mishkin, 1982; Milner \& Goodale, 1995). Although a similar distinction between visual and spatial processing in WM was not made in Baddeley's model, many behavioral (Baddeley \& Lieberman, 1980; Logie \& Marchetti, 1991; Tresch, Simmamon \& Seamon, 1993; Hecker \& Mapperson, 1997), neuropsychological (Farah, Hammond, Levine, \& Calvanio, 1988), ERP (Mecklinger \& Muller, 1996; Bosch, Mecklinger \& Friederici, 2001) 
and imaging (Courtney, Ungerleider, Keil \& Haxby, 1996; Wager \& Smith, 2003; Ventre- Dominey et al., 2005) studies converge to that conclusion.

\section{Spatial Attention, VSWM, and Oculomotor Programming}

Spatial attention is necessary for maintaining or rehearsing spatial information in visuo-spatial working memory (VSWM) (Awh, Vogel \& Oh, 2006). Attention may be involved in VSWM as a rehearsal mechanism similar to the articulatory control process in verbal WM (Smyth \& Scholey, 1994; Logie, 1995). In this conception, direction of attention stores spatial information in a way analogous to the storing of verbal information by rehearsal. Awh, however, marshals physiological and behavioral evidence implicating orienting (Awh \& Jonides, 2001; Awh, Anllo-Vento, \& Hillyard, 2000; Awh et al., 1999; Postle, Awh, Jonides, Smith, \& D'Esposito, 2004; Awh, Jonides, \& Reuter-Lorentz, 1998). Orienting may not be the only strategy for rehearsing spatial information, however (Belopolsky \& Theeuwes, 2009); oculomotor factors may be involved. Visual orienting is often coupled with eye movements. Behavioral (Rizzolatti, Riggio, Dascola, \& Umiltá, 1987), imaging (Corbetta et al., 1998), and single-cell (Kustov \& Robinson, 1996; Bichot, Rao, \& Schall, 2001; Hanes, Patterson, \& Schall, 1998) studies relate attention to oculomotor programming. Other behavioral studies compare the effects of various eye movements and attention shifts on VSWM (Postle, Idzikowski, Della Sala, Logie, \& Baddeley, 2006; Lawrence, Myerson, \& Abrams, 2004; Pearson \& Sahraie, 2003). An integrated understanding of all three processes remains tenuous, however.

The possible association between attention and oculomotor control is now explored through microsaccades, tiny eye movements that persist during visual fixation (Martinez-Conde, Macknik, \& Hubel, 2004; Ratliff \& Riggs, 1950). Microsaccades show the same amplitude to velocity profile as ordinary saccades (the "main sequence," Zuber, Stark, \& Cook, 1965) but with amplitudes too small to be measured without sensitive equipment (maximum amplitudes in the literature range from $20 \mathrm{~min}$ arc to $1^{\circ}$ ) and are thought to occur involuntarily at an average rate of about one to two per second during idle fixation (Ditchburn \& Ginsborg, 1953). Small saccades can occur at the greater end of that amplitude range (30 to $60 \mathrm{~min}$ arc) during reading (Cunitz \& Steinman, 1969). They are arguably goal-directed and not involuntary like microsaccades. Hafed \& Clark (2002) have shown with static fixation tasks, however, that results do not differ when including microsaccades greater than $0.5^{\circ}$; results were identical even when including only microsaccades of $30 \mathrm{~min}$ arc up to $2^{\circ}$. Microsaccades have been correlated with shifts of covert attention (Hafed \& Clark, 2002; Engbert \& Kliegl, 2003; Laubrock, Engbert, \& Kliegl, 2005; Turatto, Valsecchi, Tamè, $\&$ Betta, 2007) and may indicate attention shifts for some tasks. Engbert \& Kliegl (2003) studied endogenous cueing (Posner, Nissen \& Ogden, 1978) while measuring microsaccades. Average microsaccade rates dropped from a baseline of $1.0 / \mathrm{sec}$ to $0.2 / \mathrm{sec}$ about $150 \mathrm{~ms}$ following cue onset, and then rose to $2.3 / \mathrm{sec}$ before falling to baseline levels again by $500 \mathrm{~ms}$ post-cue. Microsaccade directions during the $300-400 \mathrm{~ms}$ post- cue interval were biased toward the cued location compared to $100-200 \mathrm{~ms}$ before cue onset. Thus, microsaccades were more frequent and showed a directional bias toward the cue at a time when central cues are most effective.

These observations led Engbert \& Kliegl to argue that microsaccades could objectively index covert orienting. Laubrock, Engbert, \& Kliegl (2005) extended the microsaccade correlation with attention to exogenous cues. Microsaccade rates were similar to those found in Engbert \& Kliegl (2003), although the directional effects were somewhat stronger for exogenous orienting. Peripheral cues induced a bias toward the cue 50-200 ms after cue presentation, an equally strong bias in the opposite direction 300-600 $\mathrm{ms}$ after the cue, and then a weaker bias back toward the cue $600-900$ ms post-cue. Bias away from the cue is suggestive of inhibition of return; other microsaccade studies share this interpretation (Galfano, Betta, \& Turatto, 2004; Betta, Galfano, \& Turatto, 2007). If microsaccades indicate covert attention shifts, can they also signal orienting in the service of VSWM rehearsal? If so, monitoring of microsaccades would offer a method for measuring orienting and attention in real time without interfering with ongoing cognitive activity.

Microsaccades might also affect retention span in VSWM. Voluntary saccades during retention decrease spatial span to a greater degree than attention shifts, which still affect span more than no secondary task at all (Pearson \& Sahraie, 2003; Lawrence et al., 2004). Those studies, though, did not explore microsaccades.

To examine whether covert orienting is a rehearsal mechanism for spatial STM, and further determine whether microsaccades could overtly signal that presence independent of RTs, we replicated all three of Awh et al.'s (1998) experiments in one study. In addition, we monitored microsaccades and examined their patterns in each of the conditions. The goal of our study, then, was first to examine the effect of intervening tasks on visual 
short-term memory, and second to investigate the role of the frequency and direction of microsaccades in influencing these tasks.

\section{Method}

Awh et al.'s (1998) first experiment presented observers with a spatial short-term memory task; during the retention interval, they performed a simple shape discrimination. Mimicking that experiment, we present a spatial short-term memory task (the location task) paired with a second task, a speeded shape discrimination, during retention. Trials with shapes appearing at cued positions should have faster choice RTs than those appearing in other locations, reflecting covert orienting to the cued location during retention. Changes in microsaccade rates following the location cue and possibly biases in their directions as an indicator of covert orienting are predicted on the basis of work relating microsaccades to attention (Hafed \& Clark, 2002; Engbert \& Kliegl, 2003; Laubrock et al., 2005; Turatto et al., 2007).

Awh et al.'s (1998) second experiment paired the same shape choice task with an identity task that required remembering not a cued location but the identity of a letter cue, and responding to whether the probe matched the cue. We replicate that experiment with an identity control condition, which should not show facilitated RTs to shape choice stimuli during retention. Also, if microsaccade rate modulations following cues reflect only covert orienting they should be absent or show directional bias following cues in the identity task.

Awh et al.'s (1998) third experiment had a similar design except that the task during the retention interval was a color choise without a spatial component. We executed a color choice condition to replicate that experiment, where accuracy in the location memory task was impaired when a color discrimination task during retention required a shift away from the location task's cued position. Most previous work correlating microsaccades with covert attention used cues in only two directions. Here we present cues radiating in all directions. Turatto et al. (2007) also cued in several directions and still found attention- related microsaccade effects after normalizing trajectories to a single cue direction. Their search task exploited the known difference between focused and distributed attention (Bravo \& Nakayama, 1992) to produce greater microsaccade rates with stronger directional effects for discriminations (determining which of two sides of a color-mismatched stimulus is notched) than for simple detections (presence of color mismatch). This precedent brings confidence to the possibility of finding direc- tional microsaccade effects in the paradigm used here.

Another cognitive faculty that could affect performance in Awh et al.'s (1998) tasks and in Belopolsky \& Theeuwes (2009) is visual imagery (Kosslyn, 1994). Although phenomenally it seems clear that visual imagery would require VSWM, the two theoretical constructs have developed independently. Recent reviews acknowledge this (Pearson, 2001; Pearson, De Beni, \& Cornoldi; 2001), although efforts have been made to link Kosslyn's "visual buffer" with the dissociated visual and spatial components of Baddeley's original model (Logie, 1995; Pearson, Logie, \& Gilhooly, 1999). If this is a viable coding strategy, the resolution of the representation should depend on memory cue eccentricity. Neither Awh et al. or Belopolsky \& Theeuwes analyzed cue eccentricity, despite using three eccentricities with one slightly beyond parafoveal vision. We analyze cue eccentricity in addition to probe displacement magnitude; reductions in memory response accuracy or increases in RT at greater eccentricity could indicate a loss of mnemonic resolution that would imply an image-based representation or rehearsal strategy.

\section{Participants}

Eighty-five UC Santa Cruz undergraduates participated for course credit. Thirty completed the shape choice condition (four left-handed, nine male), 30 more completed the identity control condition (three lefthanded, two ambidextrous, nine male), and 25 completed the color choice condition (one left-handed, nine male). All had normal vision or corrective contact lenses.

\section{Apparatus}

Stimuli were presented on a 19" CRT monitor with $1152 \times 864$ resolution at $85 \mathrm{~Hz}$ refresh rate. Unless otherwise noted, all stimuli were black on a white background to minimize stray-light artifacts. Responses were entered bimanually with pointing fingers on opposing buttons of a USB mouse. Eye movements were recorded monocularly with a Bouis infrared Oculometer (Bach, Bouis, \& Fischer, 1983) sampled at $1 \mathrm{kHz}$ by a National Instruments analog-digital converter. Spatial resolution was $<$ $0.01^{\circ}$ (36 sec arc), allowing detection of even the smallest microsaccades. Analog oculometer output was also routed to an oscilloscope on the experimenter's desk. The head was immobilized with a bitebar that ensured a 55 $\mathrm{cm}$ viewing distance from the cornea to the screen surface, and alignment of the left eye with the center of the screen. Randomization, timing, and presentation of stimuli as well as recording of behavioral responses and con- 
trol of the analog-digital converter were performed by software written in Matlab (v7.1) with the Psychophysics Toolbox (v2.0; Brainard \& Pelli, 1997).

\section{Procedure}

Practice. Participants were instructed to fixate while doing trials, and were aware that their eye movements would be monitored in the main experiment. They first practiced the memory task alone until they met the accuracy criterion. Performance was evaluated every 15 trials to determine whether they met the criterion on those trials, and if not they practiced for another 15 trials until they could. The criterion value was $70 \%$ for memory tasks, and $80 \%$ or $90 \%$ respectively for color and shape tasks (see below). After meeting the memory task accuracy criterion, participants practiced the choice task alone until meeting another criterion performance level through the same 15-trial evaluation process. A final practice phase combined memory and choice tasks occurring at the same frequency as in experimental trials. Participants again did 15 trials at a time until criterion performance levels could be maintained for both the memory and choice tasks.

Calibration. Participants fixated calibration points $5^{\circ}$ and $1^{\circ}$ away from the zero-point in each of four cardinal directions. Next the experimenter adjusted the zero-point and $\mathrm{X}$ and $\mathrm{Y}$ gain settings on an oscilloscope to magnify the calibrated region, permitting sensitive monitoring of gaze stability.

Experimental Trials. With gaze within the calibrated region, the experimenter pressed a key to initiate a trial. The experimenter could reject trials with saccades outside the calibrated region. These trials were recycled into the block queue to be completed before the block conclusion. Participants were invited to take quick breaks between blocks, and gaze calibration preceded the beginning of each one.

\section{Memory Tasks}

A $2^{\circ}$ fixation cross appeared throughout each trial. After $500 \mathrm{~ms}$, a $400 \mathrm{~ms}$ cue appeared. Three imaginary circles (radii of $4^{\circ}, 4.8^{\circ}$, and $5.5^{\circ}$ ) surrounded central fixation, each containing cue positions at $10^{\circ}$ increments. At cue offset a $5 \mathrm{sec}$ retention interval began, concluding with a probe that remained visible until response. Participants were asked to respond as quickly as possible to the probe while remaining very accurate. An error tone sounded during the inter-trial interval (ITI) following misses or false alarms.
Location condition: Participants pressed the right button if the probe was in the same location as the cue, or the left button if it shifted inward toward fixation (2AFC).

Identity condition: This was identical to the location task except that participants pressed the right button when the probe matched the cue (same letter), or the left button when it did not (different letter). Cues and probes were lower and uppercase letters, respectively. Probe identity was varied between that of the cue letter (50\% of trials) and any other letter. Half of the location task trials were 'match' trials with probe stimuli appearing in the same location as the cue. The other half were 'miss' trials divided equally into three levels of displacement toward fixation $\left(0.7^{\circ}, 2.0^{\circ}\right.$, or $\left.2.7^{\circ}\right)$.

\section{Choice Tasks}

Two types of 2AFC discriminations were nested in the retention interval of the memory tasks (Figure 1). Choice stimuli began $2.5 \mathrm{sec}$ into retention. Participants were asked to respond as quickly as possible on choice tasks without sacrificing accuracy or performance on the memory task. Feedback was given as a tone during the ITI after error trials, and always followed any memory task feedback.

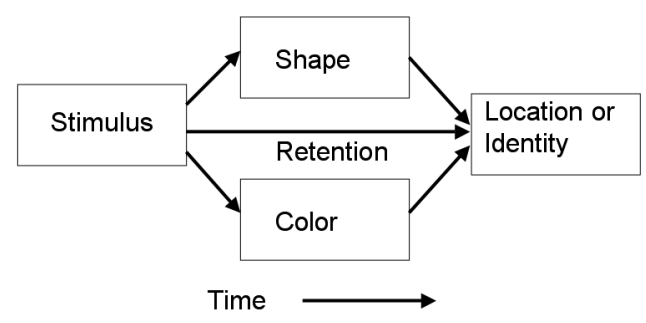

Figure 1. Memory and choice tasks. A fixation cross preceded the stimulus. The observer saw the stimulus for the retention task, then performed the shape or color tasks during the retention interval. Finally, the observer responded with either the location or the identity of the retention stimulus.

Shape choice: Stimuli were two distinctly different line patterns. Each shape corresponded to one of the two mouse buttons.

Color choice: Two independent variables were ma- 
nipulated between blocks. Size and location of a colored circle were varied such that in 'static' blocks it was $8.6^{\circ}$ in diameter, centered on the fixation cross, whereas during 'shift' blocks it was $0.9^{\circ}$ and appeared centered at one of the 36 positions on the circle of the same eccentricity as the memory task cue. Attention would need to shift to discriminate colors of small peripherally presented targets, but could remain fixed (static) at the center of the screen for the larger targets (Awh et al., 1998). As another between-block variable, participants either responded to or ignored the color choice stimulus. Color values were the same as used by Awh et al. (1998): Discrimination of circles in static blocks was between two shades of blue (hexadecimal values $0000 \mathrm{ff}$ and 2600bf) or red (ff2000 and e50036), and in shift blocks red (800000) and pink (800080) or blue (020080) and purple (530080). Participants saw and responded to only one of each of these color pairs during static or shift blocks, counterbalanced across participants.

\section{Memory Response Analysis}

Response accuracy and RT data were submitted to one- way repeated measures ANOVAs unless otherwise noted. Probe displacement was analyzed in all conditions to determine the effect of displacement magnitude over the delay. Cue eccentricity was also analyzed in each condition to see whether the distance between fixation and cue affected the memory representation.

\section{Gaze Data Processing}

Microsaccade Direction: Microsaccade trajectories were shifted relative to the cue position on each trial, such that all cue positions were normalized to $0^{\circ}$ (Turatto et al., 2007). Directional microsaccade rate was then computed as the difference between microsaccade rates toward and away from the cue (Hafed \& Clark, 2002) within a $120 \mathrm{~ms}$ window, then averaging over trials and participants as $60 \mathrm{~ms}$ window $( \pm 30 \mathrm{~ms})$ for each sample. The resulting functions were averaged over trials and participants.

Microsaccade Rate: Event data (microsaccade onsets relative to trial events) were averaged in a moving with non-directional microsaccade rate before taking the difference. Inferential comparisons were made to a surrogate distribution representing the null hypothesis of no timespecific directional modulation, defined by randomly reassigning (without replacement) onset times among directional microsaccades in each trial and averaging 1000 directional rate function slow-pass filtered with a Gaussian (bandwidth 6 samples at half maximum). An example depicting gaze traces before and after smoothing can be seen in Figure 2. The grey line and dots represent the unsmoothed raw values; the solid black line is the signal after smoothing. Noise in the raw traces comes from machine noise and oculomotor tremor, with the relative contributions of those factors being indeterminate.

Microsaccade Detection: The Engbert \& Kliegl (2003) algorithm was used to detect microsaccades with slight modifications; (a) the Gaussian smoothing process provided ample noise reduction, eliminating the need to perform their velocity transformation, which computed velocity within a moving average window, (b) our oculometer is monocular, so we did not filter microsaccades at the $1 \mathrm{kHz}$ sampling rate for binocularity, (c) the algorithm was adapted to operate (d) a minimum interval of $20 \mathrm{~ms}$ between microsaccades was required to avoid inclusion of overshoot corrections (Troncoso, Macknik, \& Martinez-Conde, 2008), and (e) minimum duration criterion was reduced from $12 \mathrm{~ms}$ to $8 \mathrm{~ms}$. This last change was prudent in our case with the greater sensitivity and sampling rate; although $1 \mathrm{kHz}$ sampling in monkeys has found no microsaccades faster than $8 \mathrm{~ms}$ (Horwitz \& Albright, 2003), Engbert \& Kliegl sampled every $4 \mathrm{~ms}$ and conservatively required at least 3 samples of duration. Velocity detection thresholds were computed as six standard deviations above the median value of a velocity time-series on a given trial; movements exceeding that velocity were noted as velocity outliers. Velocity outliers that did not exceed $1^{\circ}$ amplitude, $100 \%$ s velocity, or 40 ms duration were classified as microsaccades. Although these criteria may be considered liberal they are not extraordinarily different from those commonly used (Hafed \& Clark, 2002; Engbert \& Kliegl, 2003; Martinez-Conde, Macknik, Troncoso, \& Dyar, 2006).

To overcome velocity artifacts, gaze data were computed from those shuffled data (Rolfs, Engbert, \& Kliegl, 2005; Betta et al., 2007). Means exceeding 1.96 standard deviations from the surrogate distribution for longer than 20 ms were compared sample-by-sample to the surrogate mean in paired two-tail t-tests with false discovery rate correction for multiple comparisons (Benjamini \& Hochberg, 1995) to determine statistical significance of directional biases. 


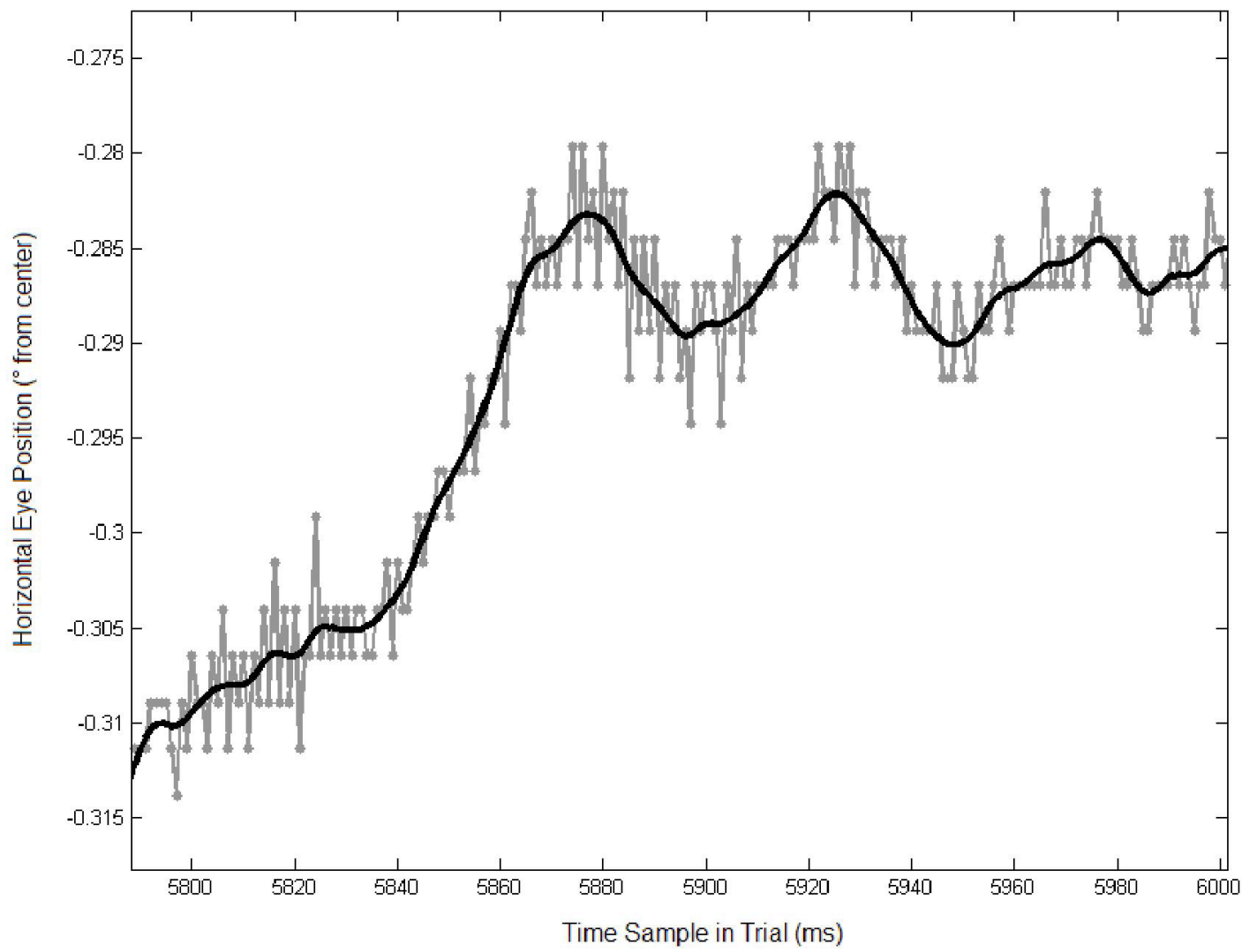

Figure 2. Example of high-resolution gaze data trace, before (grey) and after (black) Gaussian smoothing during fixation. Labeled range is $0.4^{\circ}$ (24 min arc).

\section{Results}

\section{Behavioral Data}

Excluding trials with responses faster than $300 \mathrm{~ms}$ or slower than $1500 \mathrm{~ms}$ resulted in exclusion of $6.8 \%$ of 8,640 total trials in the shape choice condition, $8.3 \%$ of 8,640 in the identity control condition, and $6 \%$ of 7,200 in the color choice condition. Trials with missing gaze data were excluded: Six $(0.07 \%), 43(0.49 \%)$, and $28(0.38 \%)$ in the shape choice, identity control, and color choice conditions respectively. Post-hoc pairwise comparisons used Tukey HSD.

Responses in the memory task were affected by the intervening choice tasks.

Accuracy: Descriptive statistics for memory task accuracies are shown in Table 1. Probe displacement magnitude strongly affected response accuracy in the location task but not the identity task. Trials with probe displacements of $0.7^{\circ}$ showed less accurate responses than those where the probe moved $2^{\circ}$ or $2.7^{\circ}$ following retention; there was still a significant difference between those two levels as well. Eccentricity affected location task accuracy differently in the shape and color choice conditions, showing that the interposed tasks affected memory. In the shape choice condition accuracy was significantly poorer on trials with cues $5.5^{\circ}$ from center versus more central locations, whereas the color choice condition showed a smaller effect that affected responses on trials with cues at $4.8^{\circ}$ and $5.5^{\circ}$ compared to $4^{\circ}$. Lastly, probe identity affected response accuracy in the identity task in the identity control condition, but not the location task in the shape choice condition. The effect is small but statistically significant: Accuracy was $2 \%$ better when the probe letter matched the cue.

Replicating Awh et al.'s (1998) Experiment 3, memory accuracy was lower when color choice stimuli were 
responded to rather than ignored. The same pairedmean, two-tailed t-test comparison in the color choice condition between shift $(M=77.4 \%, S D=5.8 \%)$ and static $(M=79.9 \%, S D=7.0 \%)$ blocks requiring responses revealed a difference, $t_{24}=2.18, p=0.04$. Similarly, we analyzed memory response accuracy as a function of choice type (match, miss, none) in the shape choice and identity control conditions in a $3 \times 2$ mixed-model ANOVA. There is a main effect of condition, $F(1,58)=226.6, p<.0001, \eta 2=0.8$, with the identity task being easier than the location task (Figure $3)$. There was also a main effect of choice type, $F(2,116)=9.39, p=.0002, \eta 2=0.14$, driven by a significant interaction, $F(2,116)=5.77, p=.004, \eta 2=$ 0.09 , with location task responses being more accurate following choice match than miss stimuli, $p=.0002$.

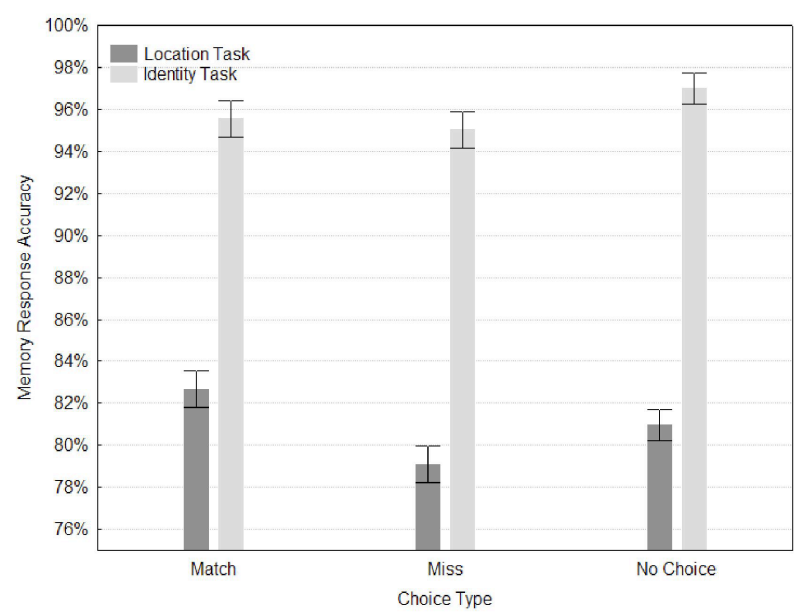

Figure 3. Memory task accuracy as a function of condition and choice type. Left: Cue location matched choice location. Center: Cue location did not match choice location. Right: No choice. Error bars represent standard error.

Reaction time: Reaction times from memory task trials with incorrect responses were excluded from analyses. Means, SDs, and ANOVA results for memory task RTs appear in Table 2. Although smaller than the effects on response accuracy, a main effect of probe displacement is present when responding to location, but not identity. The $2.7^{\circ}$ displacements were responded to fastest, followed by $2.0^{\circ}$ (a significant difference in shape choice but not color choice trials). Longer RTs occurred for $0.7^{\circ}$ displacements, not surprising considering the relatively poor accuracy of such responses. Cue eccentricity exerted a small RT main effect in the shape choice condition but not in the identity control or color choice conditions. Finally, re- sponses on identity task trials with different letters for cue and probe were about $80 \mathrm{~ms}$ faster than those with matching letters. No such effect was shown in the shape choice condition's location task

\section{Choice Responses}

Shape choice: In the shape choice and identity control conditions the choice stimulus location was the same as the location task cue (choice match) on $1 / 3$ of trials, and on another $1 / 3$ the locations were different (choice miss), comprising two levels of the choice type variable. The third level of choice type, when no choice stimulus appears, was not included for obvious reasons. Accuracy was high in the shape choice condition for choice match $(M=98.47 \%, S D=12.27 \%)$ and miss responses $(M=98.51 \%, S D=12.11 \%)$. In the identity control condition choice match $(M=98.99 \%$, $S D=1.73 \%)$ and miss $(M=98.97 \%, S D=2.09 \%)$ responses were at ceiling. Only RTs from trials with accurate choice and memory responses were analyzed. In a 2 × 2 mixed-model ANOVA, choice type (match or miss) was a within-subjects factor and condition (shape choice or identity control) the between-subjects factor. The critical comparison was between choice match and miss RTs in the shape choice condition. Facilitation for match trials in that but not the identity control condition would support Awh et al.'s (1998) argument for covert orienting underlying rehearsal of spatial location. Belopolsky and Theeuwes (2009), on the other hand, found inhibition of choice match responses and argued that covert attention was not necessary for rehearsal. There was no significant choice type $\mathrm{x}$ condition interaction, $F(1,58)<1$, signaling no effect in either direction.

Color choice: Responses were more accurate in static blocks (large stimuli in center of screen, $M=$ $98.02 \%, S D=3.17 \%$ ) than in shifting blocks (smaller stimuli at peripheral locations, $M=93.3 \%, S D=$ $7.28 \%$ ). Repeated-measures ANOVA confirmed the significance of this effect, $F(1,24)=10.69, p=$ $.003, \eta 2=0.31$. Another $p$ repeated-measures ANOVA showed there was no effect of eccentricity on response accuracy in the shift blocks, $F(2,48)<1$. Static blocks had faster responses $(M=619 \mathrm{~ms}, S D=131 \mathrm{~ms})$ than shift blocks $(M=811 \mathrm{~ms}, S D=146 \mathrm{~ms})$, and repeatedmeasures ANOVA confirmed this effect's significance, $F(1,24)=78.48, p<.0001, \eta 2=0.77$. As with response accuracy, repeated-measures ANOVA showed no eccentricity effects for RTs, $F(2,48)<1$. 


\begin{tabular}{|c|c|c|c|c|c|c|c|c|}
\hline Factor & Condition & & Levels & & $d f$ & $F$ & $p$ & $h_{p}^{2}$ \\
\hline & & $0.7^{\circ}$ & $2^{\circ}$ & $2.7^{\circ}$ & & & & \\
\hline \multirow{3}{*}{$\begin{array}{c}\text { Probe Displace- } \\
\text { ment }\end{array}$} & $\begin{array}{l}\text { Shape } \\
\text { Choice }^{\mathrm{a}}\end{array}$ & $\begin{array}{l}31_{\mathrm{a}} \pm \\
12 \%\end{array}$ & $\begin{array}{c}91_{\mathrm{b}} \pm \\
8 \%\end{array}$ & $\begin{array}{c}97_{\mathrm{c}} \pm \\
4 \%\end{array}$ & 2,58 & 728.1 & $<.001$ & 0.97 \\
\hline & $\begin{array}{l}\text { Identity Con- } \\
\text { trol }^{\mathrm{a}}\end{array}$ & $96 \pm 5 \%$ & $95 \pm 5 \%$ & $96 \pm 4 \%$ & 2,58 & 0.9 & 0.42 & - \\
\hline & $\begin{array}{c}\text { Color } \\
\text { Choice }^{\mathrm{b}}\end{array}$ & $\begin{array}{c}26_{a} \pm \\
10 \%\end{array}$ & $\begin{array}{l}85_{b} \pm \\
11 \%\end{array}$ & $\begin{array}{c}96_{c} \pm \\
4 \%\end{array}$ & 2,48 & 697.6 & $<.001$ & 0.97 \\
\hline \multirow{4}{*}{ Cue Eccentricity } & & $4^{\circ}$ & $4.8^{\circ}$ & $5.5^{\circ}$ & & & & \\
\hline & $\begin{array}{l}\text { Shape } \\
\text { Choice }^{\mathrm{a}}\end{array}$ & $\begin{array}{c}83_{a} \pm \\
5 \%\end{array}$ & $\begin{array}{c}82_{\mathrm{a}} \pm \\
6 \%\end{array}$ & $\begin{array}{c}78_{\mathrm{b}} \pm \\
5 \%\end{array}$ & 2,58 & 14.3 & $<.001$ & 0.33 \\
\hline & $\begin{array}{c}\text { Identity Con- } \\
\text { trol }^{\mathrm{a}}\end{array}$ & $96 \pm 4 \%$ & $96 \pm 4 \%$ & $96 \pm 4 \%$ & 2,58 & 0.2 & 0.87 & - \\
\hline & $\begin{array}{c}\text { Color } \\
\text { Choice }^{\mathrm{b}}\end{array}$ & $\begin{array}{c}82_{a} \pm \\
6 \%\end{array}$ & $\begin{array}{c}78_{\mathrm{b}} \pm \\
5 \%\end{array}$ & $\begin{array}{c}76_{b} \pm \\
8 \%\end{array}$ & 2,48 & 7.9 & $<.01$ & 0.25 \\
\hline & & Same & & Different & & & & \\
\hline \multirow{2}{*}{ Cue Identity } & $\begin{array}{l}\text { Shape } \\
\text { Choice }^{\mathrm{a}}\end{array}$ & $81 \pm 4 \%$ & & $81 \pm 4 \%$ & 1,29 & 1.8 & 0.19 & - \\
\hline & $\begin{array}{l}\text { Identity Con- } \\
\text { trol }^{\mathrm{a}}\end{array}$ & $97 \pm 3 \%$ & & $95 \pm 5 \%$ & 1,29 & 6.5 & $<.05$ & 0.18 \\
\hline
\end{tabular}

Note. Levels with identical subscripts do not have significantly different means at $\mathrm{p}<.05$ in the Tukey honestly significant difference comparison. Eta partial squared is given in the rightmost column as effect size; dashes indicate no main effect found.

${ }^{\mathrm{a}} \mathrm{N}=30 .{ }^{b} \mathrm{~N}=25$.

Table 1. Means and Standard Deviations (Percent) for Memory Task Accuracy ANOVAs. 


\begin{tabular}{|c|c|c|c|c|c|c|c|c|}
\hline \multirow[t]{2}{*}{ Factor } & \multirow[t]{2}{*}{ Condition } & \multicolumn{3}{|c|}{ Levels } & \multirow[t]{2}{*}{$d f$} & \multirow[t]{2}{*}{$F$} & \multirow[t]{2}{*}{$p$} & \multirow[t]{2}{*}{$\eta_{p}^{2}$} \\
\hline & & $0.7^{\circ}$ & $2^{\circ}$ & $2.7^{\circ}$ & & & & \\
\hline \multirow{3}{*}{$\begin{array}{l}\text { Probe Dis- } \\
\text { placement }\end{array}$} & $\begin{array}{c}\text { Shape } \\
\text { Choice }^{\mathrm{a}}\end{array}$ & $\begin{array}{c}890_{\mathrm{a}} \pm \\
126 \mathrm{~ms}\end{array}$ & $\begin{array}{c}747_{\mathrm{b}} \pm \\
104 \mathrm{~ms}\end{array}$ & $\begin{array}{c}700_{\mathrm{c}} \pm 88 \\
\mathrm{~ms}\end{array}$ & 2,58 & 87.2 & $<.001$ & 0.75 \\
\hline & $\begin{array}{l}\text { Identity } \\
\text { Control }^{\mathrm{a}}\end{array}$ & $\begin{array}{c}742 \pm \\
139 \mathrm{~ms}\end{array}$ & $\begin{array}{c}746 \pm 160 \\
\mathrm{~ms}\end{array}$ & $\begin{array}{c}745 \pm 141 \\
\mathrm{~ms}\end{array}$ & 2,58 & 0.2 & 0.81 & - \\
\hline & $\begin{array}{c}\text { Color } \\
\text { Choice }^{b}\end{array}$ & $\begin{array}{c}834_{\mathrm{a}} \pm \\
138 \mathrm{~ms}\end{array}$ & $\begin{array}{c}706_{\mathrm{b}} \pm \\
133 \mathrm{~ms}\end{array}$ & $\begin{array}{l}683_{\mathrm{b}} \pm \\
130 \mathrm{~ms}\end{array}$ & 2,48 & 87.0 & $<.001$ & 0.78 \\
\hline \multirow{4}{*}{ Cue Eccentricity } & & $4^{\circ}$ & $4.8^{\circ}$ & $5.5^{\circ}$ & & & & \\
\hline & $\begin{array}{c}\text { Shape } \\
\text { Choice }^{\mathrm{a}}\end{array}$ & $\begin{array}{l}751_{\mathrm{a}} \pm \\
89 \mathrm{~ms}\end{array}$ & $\begin{array}{c}771_{\mathrm{b}} \pm 96 \\
\mathrm{~ms}\end{array}$ & $\begin{array}{c}765_{\mathrm{b}} \pm \\
104 \mathrm{~ms}\end{array}$ & 2,58 & 3.7 & $<.05$ & 0.11 \\
\hline & $\begin{array}{l}\text { Identity } \\
\text { Control }^{\mathrm{a}}\end{array}$ & $\begin{array}{c}753 \pm \\
145 \mathrm{~ms}\end{array}$ & $\begin{array}{c}748 \pm 141 \\
\mathrm{~ms}\end{array}$ & $\begin{array}{c}755 \pm 141 \\
\mathrm{~ms}\end{array}$ & 2,58 & 0.7 & 0.49 & - \\
\hline & $\begin{array}{l}\text { Color } \\
\text { Choice }^{b}\end{array}$ & $\begin{array}{c}700 \pm \\
137 \mathrm{~ms}\end{array}$ & $\begin{array}{c}702 \pm 129 \\
\mathrm{~ms}\end{array}$ & $\begin{array}{c}712 \pm 135 \\
\mathrm{~ms}\end{array}$ & 2,48 & 1.6 & 0.22 & - \\
\hline & & \multicolumn{2}{|c|}{ Same } & Different & & & & \\
\hline \multirow{2}{*}{ Cue Identity } & $\begin{array}{c}\text { Shape } \\
\text { Choice }^{\mathrm{a}}\end{array}$ & \multicolumn{2}{|c|}{$762 \pm 95 \mathrm{~ms}$} & $762 \pm 92 \mathrm{~ms}$ & 1,29 & 0.1 & 0.99 & - \\
\hline & $\begin{array}{l}\text { Identity } \\
\text { Control }^{\text {a }}\end{array}$ & \multicolumn{2}{|c|}{$793 \pm 144 \mathrm{~ms}$} & $11 \pm 145 \mathrm{~ms}$ & 1,29 & 49.7 & $<.001$ & 0.63 \\
\hline
\end{tabular}

Note. Levels with identical subscripts do not have significantly different means at $\mathrm{p}<.001$ in the Tukey honestly significant difference comparison. Eta partial squared is given in the rightmost column as effect size; dashes indicate no main effect found.

${ }^{\mathrm{a}} \mathrm{N}=30 .{ }^{\mathrm{b}} \mathrm{N}=25$.

Table 2. Means and Standard Deviations (msec) for Memory Task Reaction Time ANOVAs.

\section{Microsaccade Data}

Descriptive Statistics: Figure 4 is a logarithmic main sequence plot of all microsaccades across conditions. Most fall within our criterion amplitude and velocity values for classification as microsaccades, with modal values of about $0.2^{\circ}\left(12\right.$ minarc) and $20^{\circ} / \mathrm{s}$.
Rate: Figure 5 shows raster plots of stimulus-locked microsaccades from 12 randomly selected trials for each participant in the three between-subject conditions, and the resulting microsaccade rate function from fixation onset through memory probe offset. Replicated from previous work is the pattern of inhibition 
following task- relevant stimulus onsets followed by a brief enhancement and then a return to baseline. Novel is the great increase in microsaccade rate following fixation onset, with no prior inhibitory period (first peak at $500 \mathrm{~ms}$ ). Figure 6 shows microsaccade rate functions within conditions as a function of choice type. Rate following choice onset $(3400 \mathrm{~ms})$ remains at baseline on trials with no choice stimulus and shows a steeper drop upon probe onset.

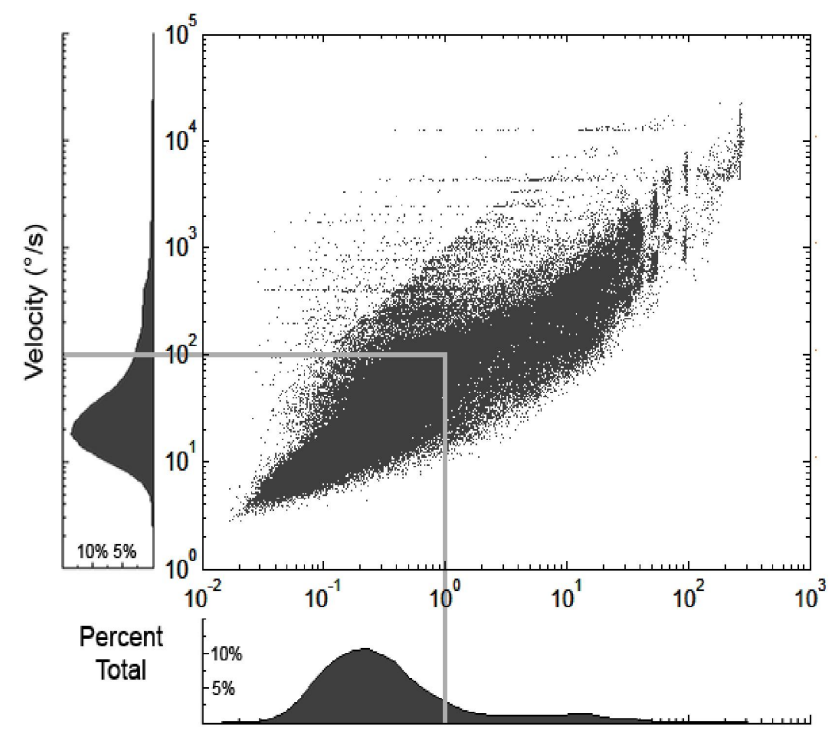

Figure 4. Frequency polygons running along the two axes impart density information in the distribution that is less obvious from the scatterplot. Light grey lines are superimposed over the data at the microsaccade amplitude and velocity thresholds.

Directions: In determining whether microsaccades indicate covert spatial attention, rate changes are less relevant than whether microsaccades show a directional bias consonant with the location cue. Figure 7 shows directional rates from all conditions in black, with positive and negative values representing a directional microsaccade bias toward and away from the cue respectively. Shaded regions delimit the 95\% confidence interval of the surrogate distribution representing the null hypothesis that microsaccade trajectories had no relationship to trial events. Thus the shaded regions represent the power of the experiment to detect a significant difference.

There was a general bias away from cued locations following cue, choice stimulus, and probe onsets in the shape choice and identity control conditions; the color choice data are noisier and more difficult to interpret. There were occasions in which mean directional rates exceeded the surrogate distribution's confidence interval, as indicated by the black line going outside the shaded region in Figure 7 . None of these

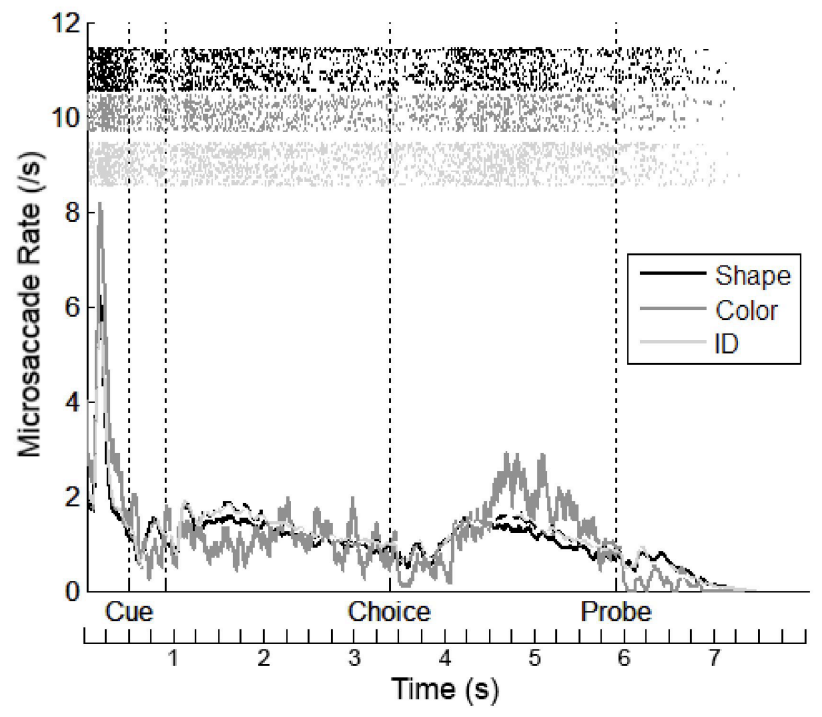

Figure 5. Stimulus-locked microsaccade rate as a function of trial event across conditions. Raster plots at the top represent raw data (microsaccade onsets). Each row contains onsets from 12 randomly selected trials performed by a unique observer. Rate functions at the bottom were computed from these data.

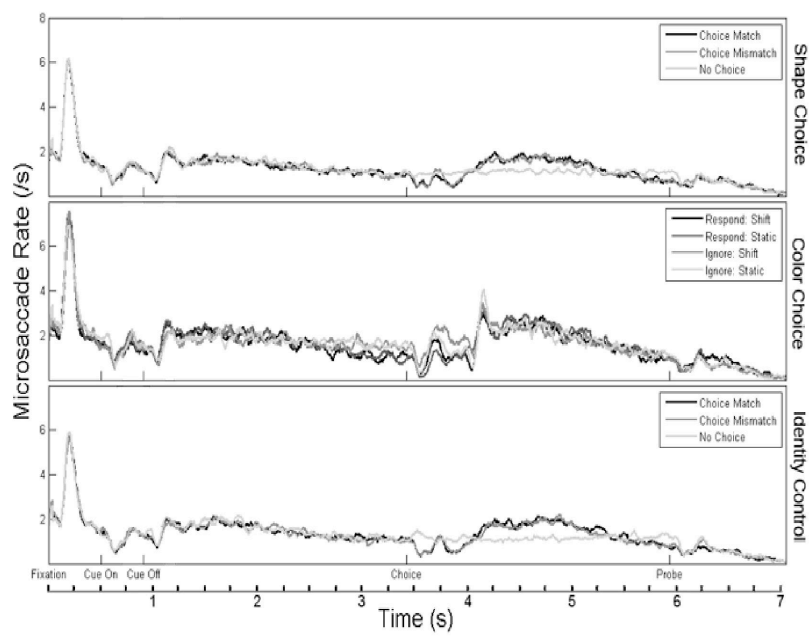

Figure 6. Stimulus onset-locked microsaccade rate functions for shape choice, color choice, and identity control conditions, all as a function of choice task.

time spans, however, approached significance when 
mean directional rates were compared to the means of the surrogate distributions.

Microsaccades During Retention. Some studies of VSWM showed that making saccades during retention negatively affected spatial span (Postle et al., 2006; Lawrence et al., 2004; Pearson \& Sahraie, 2003). Microsaccades occurring during the retention interval were counted and averaged by the number of correct or incorrect trials and then analyzed with condition as a between-subjects factor in a $2 \times 3$ mixed-model ANOVA. Although the average number of microsaccades did not vary significantly during retention between correct and incorrect trials, $F(1,82)=2.02, \mathrm{p}=0.16$, there was a significant difference in the average number between tasks, $F(2,82)=5.39, p=.006$. Post-hoc pairwise comparison showed that more microsaccades occurred during retention in the color condition $(M=7.74, S D=2.69)$ than the shape condition $(M=5.4, S D=2.69), p=.005$.

\section{Discussion and Conclusions}

On location miss trials, shape and color choice participants are increasingly accurate and quick responding to larger probe displacements. These effects are generally the same as from previous studies, at least qualitatively (Awh et al., 1998; Belopolsky and Theeuwes, 2009). However, our participants were slower and less accurate at detecting the smallest $\left(0.7^{\circ}\right)$ displacements, which could indicate they were performing the location task with a lower resolution representation. Higher accuracy with larger displacements in our experiment versus previous studies suggests a detection bias toward the larger end of the range.

Contrary to predictions from cueing paradigms, microsaccades did not appear to show any directional bias that could indicate the deployment of covert spatial attention. Although successful location task performance requires cue locations to be encoded in all directions from central fixation it does not result in microsaccade trajectories in those directions. Most studies linking microsaccades with attention showed inhibition in response to visual onsets followed by a brief increase in microsaccade rate (Bridgeman \& Palca, 1980; Winterson \& Collewijn, 1976; Engbert \& Kliegl, 2003; Laubrock et al., 2005; Rolfs et al., 2005); we generally replicate that pattern. The pattern is most striking in the contrast between shape choice trials with and without
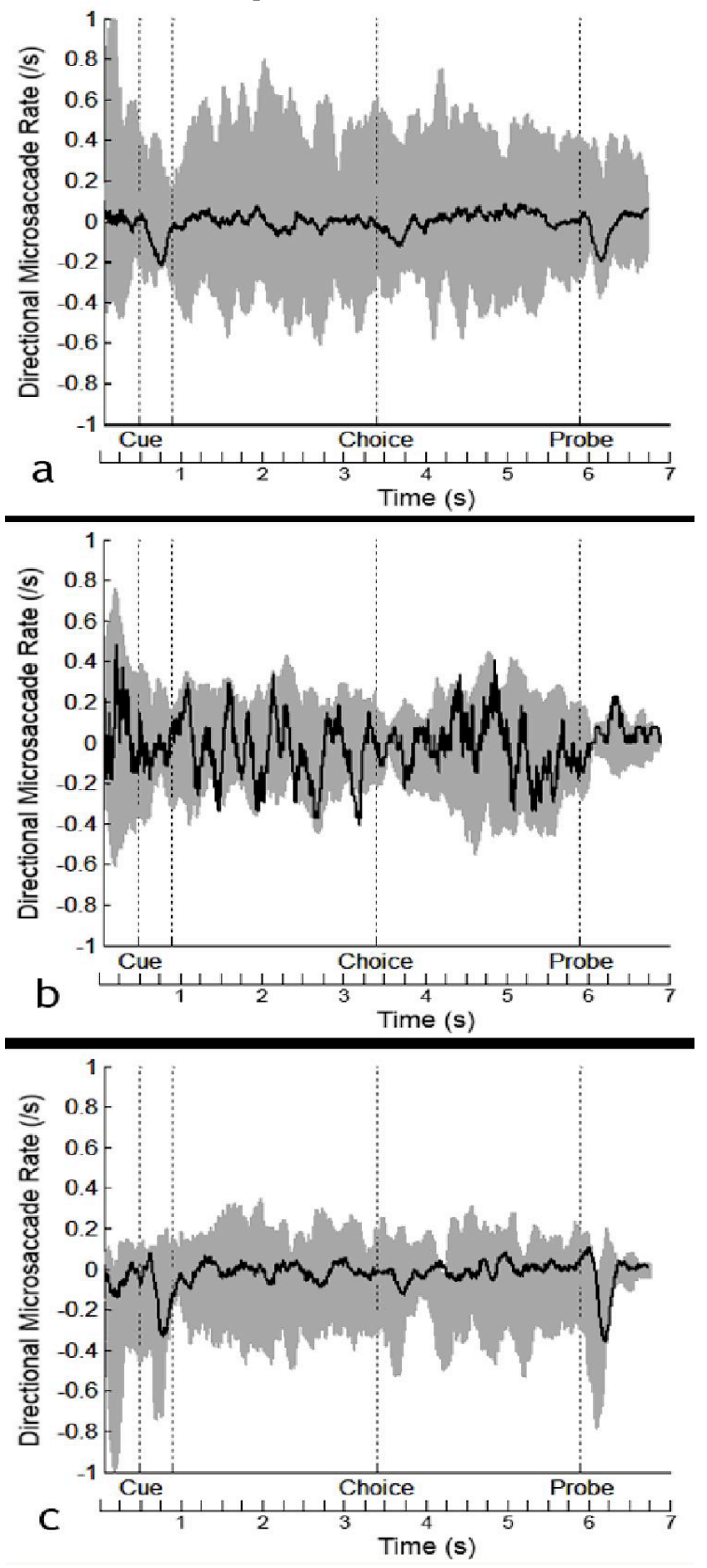

Figure 7. Directional microsaccade rates for (a) shape choice, (b) color choice, and (c) identity control conditions (black lines). Shaded regions indicate 1.96 SDs from the mean of the surrogate distribution representing the null hypothesis of no time-dependent directional effects. 
stimuli. Novel, however, is the large microsaccade rate peak following fixation onset with no apparent inhibition preceding it. These microsaccades probably realigned gaze with the fixation cross, as a blank screen during the ITI could have disoriented gaze.

Lastly, the number of microsaccades occurring during retention appears to be unrelated to memory performance, unlike performing overt saccades and even making covert shifts of attention. Voluntary saccades during retention interfere with spatial WM tasks according to Pearson \& Sahraie (2003), Lawrence et al. (2004) and Postle et al. (2006), but their methods did not consider involuntary microsaccade activity. If microsaccades also interfered with VSWM, accuracy should diminish as the number of microsaccades increases. We demonstrate no difference between mean microsaccade frequency in correct vs. incorrect location task trials. This could mean that the location task does not rely on the spatial WM resources linked to oculomotor programming by previous work, or that microsaccades do not encroach upon spatial WM in the same manner as voluntary saccades. Though our data cannot distinguish between these possibilities, we find the second alternative to be more likely. Because fixation is maintained during microsaccades, the small gaze shifts would not be related to shifts of attention. This is what differentiates microsaccades from larger saccades.

Future studies should first ascertain whether larger, voluntary saccades interfere with location task performance. Attention shifts associated with voluntary saccades rather than the physical saccades themselves may disrupt VSWM in studies reporting such findings, thereby excluding microsaccades with no attentional component from the category of events that disrupts VSWM. Covert attention shifts and saccades create statistically different amounts of interference (Pearson \& Sahraie, 2003; Lawrence et al., 2004), suggesting a differential involvement of VSWM in those two actions. Any oculomotor component to VSWM interference might be negligible for microsaccades if the interference is related to saccade amplitude.

We sought to determine whether microsaccade trajectories during retention in the location task coincided with the direction of the location cue, perhaps as evidence for the presence of covert attention driving rehearsal during retention. Microsaccades in cueing paradigms are biased in the direction that central and peripheral cues arguably drive attention (Engbert \& Kliegl, 2003; Hafed \& Clark, 2002) and previous be- havioral results have suggested that VSWM rehearsal is facilitated by covert orienting (Awh et al., 1998). We had hoped it possible to extend the findings from cueing studies to VSWM rehearsal such that it could be monitored unobtrusively. Although our method was capable of recording and unambiguously isolating microsaccades as data, they did not relate to the cognitive underpinnings of our task. We have reproduced some of the rate responses to stimulus onsets seen by others (Engbert \& Kliegl, 2003; Rolfs et al., 2005; Rolfs et al., 2008). We also found rate increases in response to the fixation cross and rate decreases at location cue offset. Most crucially, though, we have not shown microsaccades to be directionally biased toward location task cues as previous studies relating attention to microsaccades. We may not have found correlations between the directions of microsaccades and the direction of attention because the two are not associated, as some suggest (Kowler \& Steinman, 1980; Tse, Sheinberg, \& Logothetis, 2002; 2004; Horowitz et al., 2007a; $2007 b$ ), or just because the task does not require covert attention (Belopolsky \& Theeuwes, 2009).

The function of microsaccades has been a controversial issue for some time. For almost as long as we have known that they exist (Ratliff \& Riggs, 1950), we have also known that stabilized images fade from perception rather quickly (Ditchburn \& Ginsborg, 1952; Pritchard, 1961). Drifts, tremor and microsaccades, though, may contribute differentially to inhibiting fading (Martinez-Conde et al., 2004). Considering the difference in receptive field sizes in the peripheral and central retina, it has been suggested that microsaccades may be necessary to refresh receptors in the periphery whereas drifts should be sufficient in the center; recent studies bolster such suspicions. Momentary decreases and increases in microsaccade frequency are correlated with the fading and reappearance, respectively, of a static grating in the periphery (Martinez-Conde et al., 2006). Also, microsaccades occur in central fixation tasks only under conditions of lower than ordinary drift-induced retinal image slip (Engbert \& Mergenthaler, 2006). Although functioning to counteract retinal fading, microsaccades can affect visual acuity negatively in that they are associated with saccadic suppression (Beeler, 1967), much like the loss of momentary visual information associated with larger saccades (Zuber \& Stark, 1966). This is probably why microsaccades tend to be inhibited during high acuity tasks (Winterson \& Collewijn, 1976; Bridgeman \& Palca, 1980), and why recent studies using attentional cueing paradigms as well as our paradigm show decreases in average microsaccade rate following the 
presentation of task relevant visual information.

There may not be a generalized function of microsaccades; in support of this idea single-cell studies have shown that spiking in visual cortex neurons is correlated with microsaccades in a context-specific manner. In monkeys, spikes during binocular rivalry of orthogonally oriented gratings showed spike suppression peaking about $100 \mathrm{~ms}$ after a microsaccade (Leopold \& Logothetis, 1998), whereas another lab showed increased spiking about $50 \mathrm{~ms}$ after a microsaccade while presenting oriented bars to the receptive field of otherwise passively fixating monkeys (MartinezConde, Macknik \& Hubel, 2000). Divergences such as these suggest an increasingly complicated situation. Our results indicate that the presence of microsaccades correlates with cognitive processes, but their direction does not correlate with task requirements.

\section{References}

Awh, E., Anllo-Vento, L., \& Hillyard, S. A. (2000). The role of spatial selective attention in working memory for locations: Evidence from eventrelated potentials. Journal of Cognitive Neuroscience, 12, 840-847.

Awh, E., \& Jonides, J. (2001). Overlapping mechanisms of attention and spatial working memory. Trends in Cognitive Sciences, 5, 119-125.

Awh, E., Jonides, J., \& Reuter-Lorenz, P. A. (1998). Rehearsal in spatial working memory. Journal of Experimental Psychology: Human Perception and Performance, 24, 780- 790.

Awh, E., Jonides, J., Smith, E. E., Buxton, R. B., Frank, L. R., Love, T., Wong, E. C., \& Gmeindl, L. (1999). Rehearsal in spatial working memory: Evidence from neuroimaging. Psychological Science, 10, 433-437.

Awh, E., Vogel, E. K., \& Oh, S.-H. (2006). Interactions between attention and working memory. Neuroscience, 139, 201-208.

Bach, M., Bouis, D., \& Fischer, B. (1983). An accurate and linear infrared oculometer. Journal of Neuroscience Methods, 9, 9-14.

Baddeley, A. D., Grant, S., Wight, E., \& Thomson, N.
(1975). Imagery and visual working memory. In P. M. A. Rabbitt \& S. Dornic (Eds.), Attention and performance $V$ (pp. 205-217). London: Academic Press.

Baddeley, A. D., \& Hitch, G. (1974). Working memory. In G. Bower (Ed.), The psychology of learning and motivation (Vol. 8). New York: Academic Press.

Baddeley, A. D., \& Lieberman, K. (1980). Spatial working memory. In R. Nickerson (Ed.), Attention and performance VI (pp. 522-539). London: Academic Press.

Beeler, G. W. (1967). Visual threshold changes resulting from spontaneous saccadic eye movements. Vision Research, 7, 769-775.

Belopolsky A.V., \& Theeuwes J. (2009). Inhibition of saccadic eye movements to locations in spatial working memory. Attention, Perception, \& Psychophysics, 71, 620-631.

Benjamini, Y., \& Hochberg, Y. (1995). Controlling the false-discovery rate: A practical and powerful approach to multiple testing. Journal of the Royal Statistical Society B, 57, 289-300.

Betta, E., Galfano, G., \& Turatto, M. (2007). Microsaccadic response during inhibition of return in a target-target paradigm. Vision Research, 47, 428436.

Bichot, N. P., Rao, S. C., \& Schall, J. D. (2001). Continuous processing in macaque frontal cortex during visual search. Neuropsychologia, 39, 972-982.

Bosch, V., Mecklinger, A., \& Friederici, A. D. (2001). Slow cortical potentials during retention of object, spatial, and verbal information. Cognitive Brain Research, 10, 219-237.

Brainard. D. H., \& Pelli, D. G. (1997). The psychophysics toolbox. Spatial Vision, 10, 433- 436.

Bravo, M. J., \& Nakayama, K. (1992). The role of attention in different visual search tasks. Perception \& Psychophysics, 5, 465-472.

Bridgeman, B., Kirch, M., \& Sperling, A. (1981). Segregation of cognitive and motor aspects of visual function using induced motion. Perception \& 
Pschophysics , 29, 336-342.

Bridgeman, B., Lewis, S., Heit, G., \& Nagle, M. (1979). Relation between cognitive and motororiented systems of visual position perception. Journal of Experimental Psychology 5, 692-700.

Bridgeman, B., \& Palca, J. (1980). The role of microsaccades in high acuity observational tasks. Vision Research, 20, 813-817.

Cocchini, G., Logie, R. H., Della Sala, S., \& MacPherson, S. E. (2002). Concurrent performance of two memory tasks: Evidence for domain-specific working memory systems. Memory \& Cognition, 30, 1086-1095.

Corbetta, M., Akbudak, E., Conturo, T. E., Snyder, A. Z., Ollinger, J. M., Drury, H. A., et al. (1998). A common network for functional areas for attention and eye movements. Neuron, 21, 761-773.

Cornoldi, C., \& Vecchi, T. (2003). A continuity approach to visuo-spatial working memory. In C. Cornoldi \& T. Vecchi (Eds.), Visuo-spatial working memory and individual differences (pp. 119134). New York, NY: Psychology Press.

Courtney, S. M., Ungerleider, L. G., Keil, K., \& Haxby, J. V. (1996). Object and spatial visual working memory activate separate neural systems in human cortex. Cerebral Cortex, 6, 39-49.

Cowan, N. (1999). An embedded process model of working memory. In A. Miyake \& P. Shah (Eds.), Models of working memory: Mechanisms of active maintenance and executive control (pp. 62-101). New York, NY: Cambridge University Press.

Cunitz, R. J., \& Steinman, R. M. (1969). Comparison of saccadic eye movements during fixation and reading. Vision Research, 9, 683-693.

Ditchburn, R. W., \& Ginsborg, B. L. (1952). Vision with a stabilized retinal image. Nature, 170, 36-37.

Ditchburn, R. W., \& Ginsborg, B. L. (1953). Involuntary eye movements during fixation. Journal of Physiology, 119, 1-17.

Engbert, R., \& Kliegl, R. (2003). Microsaccades uncover the orientation of covert attention. Vision Research, 15, 431-436.
Engbert, R., \& Mergenthaler, K. (2006). Microsaccades are triggered by low retinal image slip. Proceedings of the National Academy of Sciences, 103, 7192-7197.

Farah, M. J., Hammond, K. M., Levine, D. N., \& Calvino, R. (1988). Visual and spatial mental imagery: Dissociable systems of representation. Cognitive Psychology, 20, 439-462.

Galfano, G., Betta, E., \& Turatto, M. (2004). Inhibition of return in microsaccades. Experimental Brain Research, 159, 400-404.

Gathercole, S. E. (1994). Neuropsychology and working memory: A review. Neuropsychology, 8, 494505 .

Hafed, Z. M., \& Clark, J. J. (2002). Microsaccades as an overt measure of covert attention shifts. Vision Research, 42, 2533-2545.

Hale, S., Myerson, J., Rhee, S. H., Weiss, C. S., \& Abrams, R. A. (1996). Selective interference with the maintenance of location information in working memory. Neuropsychology, 10, 228-240.

Hanes, D. P., Patterson, W. F., Schall, J. D. (1998). Role of frontal eye fields in countermanding saccades: Visual, movement, and fixation activity. Journal of Neurophysiology, 79, 817-834.

Hecker, R., \& Mapperson, B. (1997). Dissociation of visual and spatial processing in working memory. Neuropsychologica, 35, 599-603.

Horowitz, T. S., Fine, E. M., Fenesik, D. E., Yurgenson, S., \& Wolfe, J. M. (2007a). Fixational eye movements are not an index of covert attention. Psychological Science, 18, 356-363.

Horowitz, T. S., Fine, E. M., Fenesik, D. E., Yurgenson, S., \& Wolfe, J. M. (2007b). Microsaccades and attention: Does a weak correlation make an index?. Psychological Science, 18, 367-368.

Horwitz, G. D., \& Albright, T. D. (2003). Short-latency fixational saccades induced by luminance increments. Journal of Neurophysiology, 90, 13331339 .

Kosslyn, S. M. (1994). Image and Brain: The Resolu- 
tion of the Imagery Debate. Cambridge, MA: MIT Press.

Kowler, E., \& Steinman, R. M. (1980). Small saccades serve no useful purpose. Vision Research, 20, 273276.

Kustov, A. A., \& Robinson, D. L. (1996). Shared neural control of attentional shifts and eye movements. Nature, 384, 74-77.

Laubrock, J., Engbert, R., \& Kliegl, R. (2005). Microsaccade dynamics during covert attention. Vision Research, 45, 721-730.

Lawrence, B. M., Myerson, J., \& Abrams, R. A. (2004). Interference with spatial working memory: An eye movement is more than a shift of attention. Psychonomic Bulletin \& Review, 1, 488-494.

Leopold, D. A., \& Logothetis, N. K., (1998). Microsaccades differentially modulate neural activity in the striate and extrastriate visual cortex. Experimental Brain Research, 123, 341-345.

Logie, R. H. (1995). Visuo-spatial working memory. Hillsdale, NJ: Erlbaum.

Logie, R. H., \& Marchetti, C. (1991). Visuo-spatial working memory: Visual, spatial or central executive? In Logie, R. H., \& Denis, M. (Eds.). Mental Images in Human Cognition (pp.105-115). Amsterdam: Elsevier.

Logie, R. H., Zucco, G. M., \& Baddeley, A. D. (1990). Interference with visual short-term memory. Acta Psychologica, 75, 55-74.

Martinez-Conde, S., Macknik, S. L., \& Hubel, D. H. (2000). Microsaccadic eye movements and firing of single cells in the striate cortex of macaque monkeys. Nature Neuroscience, 3, 251-258.

Martinez-Conde, S., Macknik, S. L., \& Hubel, D. H. (2004). The role of fixational eye movements in visual perception. Nature Reviews Neuroscience, $5,229-240$

Martinez-Conde, S., Macknik, S. L., Troncoso, X. G., \& Dyar, T. A. (2006). Microsaccades counteract visual fading during fixation. Neuron, 49, 297305 .
Mecklinger, A., \& Muller, N. (1996). Dissociations in the processing of "what" and "where" information in working memory: An event-related potential analysis. Journal of Cognitive Neuroscience, 8, 453-473.

Milner, A. D., \& Goodale, M. A. (1995). The visual brain in action. Oxford, England: Oxford University Press.

Miyake, A., \& Shah, P. (1999). Models of working memory: Mechanisms of active maintenance and executive control. New York, NY: Cambridge.

Pearson, D. G., (2001). Imagery and the visuo-spatial sketchpad. In Andrade, J. (Ed.), Working memory in perspective, (pp. 33-59). Hove, England: Psychology Press.

Pearson, D. G., Logie, R. H., \& Gilhooly, K. (1999). Verbal representations and spatial manipulation during mental synthesis. European Journal of Cognitive Psychology, 11, 295-314.

Pearson, D. G., \& Sahraie, A. (2003). Oculomotor control and the maintenance of spatially and temporally distributed events in visuo-spatial working memory. Quarterly Journal of Experimental Psychology, 56A, 1089-1111.

Posner, M. I., Nissen, M. J., \& Ogden, W. C. (1978). Attended and unattended processing modes: The role of set in spatial locations. In H. L. Pick \& B. J. Saltzman (Eds.), Modes of perceiving and processing information (pp. 137-158). Hillsdale, NJ: Erlbaum.

Postle, B. R., Awh, E., Jonides, J., Smith, E. E., \& D'Esposito, M. (2004). The where and how of attention-based rehearsal in spatial working memory. Cognitive Brain Research, 20, 194-205.

Postle, B. R., Idzikowski, C., Della Sala, S., Logie, R. H., \& Baddeley, A. D. (2006). The selective disruption of spatial working memory by eye movements. Quarterly Journal of Experimental Psychology, 59, 100-120.

Pritchard, R. M. (1961). Stabilized images on the retina. Scientific American, 204, 72-78.

Ratliff, F., \& Riggs, L. A. (1950). Involuntary motions of the eye during monocular fixation. Journal of 
Experimental Psychology, 40, 687-700.

Rizzolatti, G., Riggio, L., Dascola, I., \& Umilta, C. (1987). Reorienting attention across the horizontal and vertical meridians: Evidence in favor of a premotor theory of attention. Neuropsychologica, $25,31-40$.

Rolfs, M., Engbert, R., \& Kliegl, R. (2005). Crossmodal coupling of oculomotor control and spatial attention in vision and audition. Experimental Brain Research, 166, 427-439.

Rolfs, M., Engbert, R., \& Kliegl, R. (2008). Toward a model of microsaccade generation: The case of microsaccade inhibition. Journal of Vision, 8, 123.

Shallice, T., (1988). From neuropsychology to mental structure. New York, NY: Cambridge.

Smyth, M. M., \& Scholey, K. A. (1994). Interference in immediate spatial memory. Memory \& Cognition, 22, 1-13.

Smyth, M. M., Pearson, N. A., \& Pendleton, L. R. (1988). Movement and working memory: Patterns and positions in space. Quarterly Journal of Experimental Psychology, 40A, 497-514.

Tresch, M. C., Sinnamon, H. M., \& Seamon, J. G. (1993). Double dissociations of spatial and object visual memory: Evidence from selective interference in intact human subjects. Neuropsychologia, $31,211-219$.

Troncoso, X. G., Macknik, S. L., \& Martinez-Conde, S. (2008). Microsaccades counteract perceptual filling in. Journal of Vision, 8, 1-9.

Tse, P. U., Sheinberg, D. L., \& Logothetis, N. K. (2002). Fixational eye movements are not affected by abrupt onsets that capture attention. Vision Research, 14, 91-99.

Tse, P. U., Sheinberg, D. L., \& Logothetis, N. K. (2004). The distribution of microsaccade directions need not reveal the location of attention. Psychological Science, 42, 1663- 1669.

Turatto, M., Valsecchi, M., Tamè, L., \& Betta, E. (2007). Microsaccades distinguish between global and local visual processing. Neuroreport, 18,
1015-1018.

Ungerleider, L. G., \& Mishkin, M. (1982). Two cortical visual systems. In D. J. Ingle, M. A. Goodale, \& R. J. W. Mansfield (Eds.), Analysis of visual behavior (pp. 549-586). Cambridge, MA: MIT Press.

Ventre-Dominey, J., Bailley, A., Lavenne, F., LeBars, D., Mollion, H., Costes, N., \& Dominey, P. F. (2005). Double dissociation in neural correlates of visual working memory: A PET study. Cognitive Brain Research, 25, 747-759.

Wager, T. D., \& Smith, E. E. (2003). Neuroimaging studies of working memory: A metaanalysis. Cognitive, Affective, \& Behavioral Neuroscience, 3, 255-247.

Wilson, J. T. L., Scott, J. H., \& Power, K. G. (1987). Developmental differences in the span of visual memory for pattern. British Journal of Developmental Psychology, 5, 249- 255.

Winterson, B. J., \& Collewijn, H. (1976). Microsaccades during finely guided visuomotor tasks. $\mathrm{Vi}$ sion Research, 16, 1387-1390.

Zuber, B. L., \& Stark, L. (1966). Saccadic suppression: Elevation of visual threshold associated with saccadic eye movements. Experimental Neurology, $16,65-79$.

Zuber, B. L., Stark, L., \& Cook, G. (1965). Microsaccades and the velocity-amplitude relationship for saccadic eye movements. Science, 150, 14591460 . 